\title{
On the development of single and multijunction solar cells with hot-wire CVD deposited active layers
}

\author{
H. Li, R.H. Franken, R.L. Stolk, J.A. Schüttauf, C.H.M. van der Werf, \\ J.K. Rath, R.E.I. Schropp* \\ Utrecht University, Faculty of Science, Department of Physics and Astronomy, SID - Physics of Devices, \\ P.O. Box 80,000, 3508 TA Utrecht, The Netherlands
}

Available online 5 February 2008

\begin{abstract}
We present an overview of the scientific challenges and achievements during the development of thin film silicon based single and multijunction solar cells with hot-wire chemical vapor deposition (HWCVD) of the active silicon layers. The highlights discussed include the development of $\mathrm{Ag} / \mathrm{ZnO}$ coatings with a proper roughness and morphology for optimal light trapping in single and multijunction thin film silicon solar cells, studies of the structural defects created by a rough substrate surface and their influence on the performance of nc-Si:H n-i-p single junction solar cells, and studies of the phase change during the growth of nc-Si:H by HWCVD and the use of a 'reverse' $\mathrm{H}_{2}$ profiling technique to achieve nc-Si:H single junction $\mathrm{n}-\mathrm{i}-\mathrm{p}$ cells with high performance. Thus far, the best AM1.5 efficiency reached for $\mathrm{n}-\mathrm{i}-\mathrm{p}$ cells on stainless-steel with HWCVD i-layers is $8.6 \%$ for single junction nc-Si:H solar cells and $10.9 \%$ for triple junction solar cells. The opportunities for further improvement of cell efficiency are also discussed. We conclude that the uniqueness of HWCVD and of the i-layers deposited with this technique require some adjustments in the strategy for optimization of single or multijunction solar cells, such as using a reverse $\mathrm{H}_{2}$ profiling technique for the deposition of nc-Si:H i-layers. However, the output performance of solar cells with HWCVD deposited i-layers is close to those with i-layers deposited by other techniques. The difference between the best nc-Si:H n$\mathrm{i}-\mathrm{p}$ cells obtained so far in our lab and the reported best $\mathrm{n}-\mathrm{i}-\mathrm{p}$ cells with PECVD i-layers can be mainly attributed to the differences in the rough substrates and to the use of rather thin i-layers.
\end{abstract}

(C) 2007 Elsevier B.V. All rights reserved.

PACS: 68.55.-a; 73.50.Pz; 73.63.Bd; 81.15.-z

Keywords: Silicon; Solar cells; Crystal growth; Nanocrystals; Photovoltaics; Chemical vapor deposition; Defects; Microcrystallinity

\section{Introduction}

Hot-wire chemical deposition (HWCVD) has been proved to be able to prepare high quality intrinsic hydrogenated amorphous silicon (a-Si:H) [1-3], proto-crystalline silicon (proto-Si:H) [4], nanocrystalline silicon (nc-Si:H) (also called microcrystalline silicon $\mu \mathrm{c}-\mathrm{Si}: \mathrm{H}$ ) $[5,6]$, polycrystalline silicon (poly-Si:H) [7] (also called high-crystallinity $\mu c-\mathrm{Si}: \mathrm{H})$ and amorphous silicon germanium (a-SiGe:H) [8] materials that are suitable for use as the active layers

\footnotetext{
${ }^{*}$ Corresponding author. Fax: +31302543165.

E-mail address: r.e.i.schropp@uu.nl (R.E.I. Schropp).
}

in silicon based thin film solar cells. Compared to conventional plasma enhanced chemical vapor deposition (PECVD), HWCVD has the property that the process is independent of electromagnetic properties of the substrate. The technique has the potential of high deposition rate; there is less dust formation and scaling up for mass production is straightforward. Therefore, it is considered to be a good alternative to conventional PECVD. At Utrecht University, we have been concentrating on developing thin film silicon based multijunction solar cells employing active layers made with HWCVD $[5,9,10]$. In this contribution, we summarize the major scientific challenges and achievements that we have experienced during the development of such devices. 


\section{Experimental details}

All the solar cells discussed in this contribution have an $\mathrm{n}-\mathrm{i}-\mathrm{p}$ structure. The structure of the triple junction solar cell is substrate (stainless-steel or Corning glass)/rough $\mathrm{Ag} /$ $\mathrm{ZnO} / \mathrm{nc}-\mathrm{Si}: \mathrm{H}$ n-i-p bottom cell/proto-SiGe: $\mathrm{H}$ n-i-p middle cell/proto-Si:H n-i-p top cell/ITO/Au grid. The silicon layers were deposited in a multi-chamber ultra-high vacuum system called PASTA [11]. Doped layers (boron and phosphorus doped nc-Si:H) and intrinsic proto-SiGe:H [12] were prepared using 13.56 MHz PECVD[13], whereas HWCVD was applied to fabricate intrinsic proto-Si:H [4] and ncSi:H $[5,9,10,14]$. Two straight Ta filaments were used for the hot-wire deposition, through which a current of $10.5 \mathrm{~A}$ was passed, yielding a wire temperature of approximately $1850^{\circ} \mathrm{C}$ in vacuum, as measured by a pyrometer. Stainless-steel foil coated with texture-grown highly reflecting $\mathrm{Ag}$ or $\mathrm{Ag}: \mathrm{AlO}_{x}$ layers was used as substrate. A single target $\mathrm{Ag}$ or $\mathrm{Ag}: \mathrm{Al}(1 \%)$ was used in an argon/oxygen ambient during sputtering. The $\mathrm{ZnO}$ and ITO layers were deposited by magnetron sputtering at room temperature, using $\mathrm{ZnO}: \mathrm{Al}(1 \%)$ and $\mathrm{In}_{2} \mathrm{O}_{3} / \mathrm{Sn}_{2} \mathrm{O}_{3}(10 \%)$ as the target material, respectively, and unless mentioned otherwise, with a typical thickness of $\sim 100 \mathrm{~nm}$ for the $\mathrm{ZnO}: \mathrm{Al}$ and $\sim 80 \mathrm{~nm}$ for the ITO. Detailed deposition conditions for the $\mathrm{Ag} / \mathrm{ZnO}$ back reflectors can be found in our earlier publications [15]. All the AM1.5 $J-V$ data shown in this article were obtained with an illumination mask to have a precise definition of the cell area. The same mask was also used for the deposition of ITO top contact. Due to the finite thickness of the mask and the accompanying shadowing effect, the thus measured $J_{\mathrm{sc}}$ values are slightly underestimated.

\section{Results and discussion}

\subsection{Textured Ag/ZnO layer growth and nc-Si:H bottom cells}

The roughness (morphology) at the back electrode/silicon interface is the key to efficient light trapping in $n-i-p$ type thin film silicon solar cells. We obtained various substrate surface roughnesses by varying the deposition condition of $\mathrm{Ag}$, rather than using the texture-etched $\mathrm{ZnO}$ approach. We studied the light trapping effects of textured $\mathrm{Ag}$ back contacts in single junction nanocrystalline silicon (nc-Si:H) n-i-p solar cells. This is also relevant for the study of light trapping in multijunction solar cells, since nc-Si:H is used as the bottom cell active layer as well. We used the theoretical description of the structure zone model, which explains the structural evolution of films during growth [15], in order to understand and to control the texture development of sputtered $\mathrm{Ag}$ back reflectors and develop a wide range of different morphological dimensions. Moreover, we introduced $\mathrm{AlO}_{x}$ during $\mathrm{Ag}$ sputtering, which acts as an inhibitor that decreases the lateral grain growth and thus delays restructuring of the surface. The Ag: $\mathrm{AlO}_{x}$ films show a combination of higher rms value at the lateral feature size that is obtained with pure $\mathrm{Ag}$ [15]. The sputtering conditions for the $\sim 100 \mathrm{~nm}$ thick $\mathrm{ZnO}$ cover layer on top of $\mathrm{Ag}$ were kept constant and it was shown that $\mathrm{ZnO}$ layer with this relatively small thickness did not introduce significant alteration of the Ag surface morphology [16].

The sizes of surface features that scatter most effectively in a nc-Si:H solar cell are around the effective wavelength of the light that is incident on the Ag surface, namely $\lambda_{\text {scat }}=\lambda_{\text {eff }}=\lambda_{\text {air }} / n_{\mathrm{ZnO} \text { :Al }}$. Because the light with wavelengths longer than around $650 \mathrm{~nm}$ reaches the back contact, and only light with wavelengths shorter than around $1100 \mathrm{~nm}$ will be absorbed by $\mathrm{Si}$, we thus considered only the relevant range of effective scattering feature sizes $\left(\lambda_{\text {scat }}\right)$. With a power spectral density (PSD) analysis, the AFM scanned surface profile can be resolved into sine profiles of various wavelengths, depending on the lateral feature sizes present on the surface. In order to achieve improved light scattering at wide angles it is considered that a surface should have dominating values of the PSD profile in the region of about $\lambda_{\text {scat }}$. We therefore quantified the contribution of the features within this range and calculated the
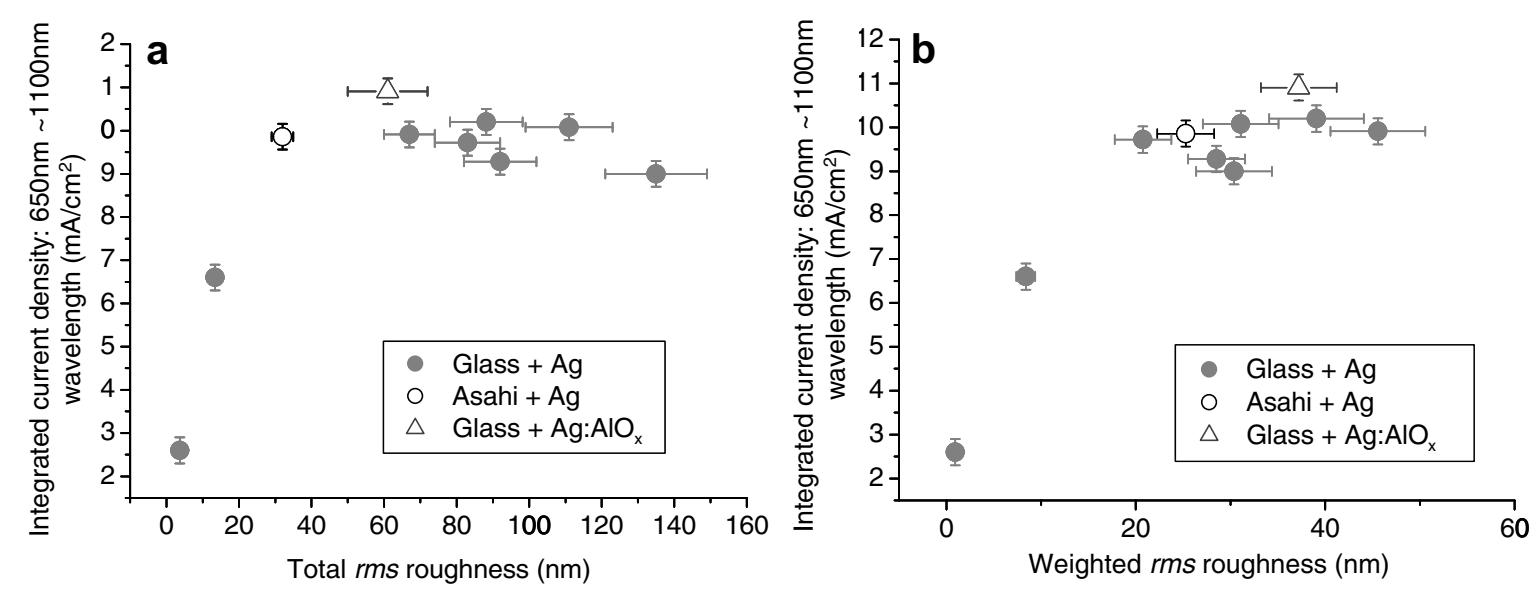

Fig. 1. The correlation between the long wavelength current density and (a) the rms roughness and (b) the weighted rms roughness. Data obtained on cells deposited on Asahi U-type substrate coated with thin Ag layers (as a reference substrate) are also shown. 
fraction of the power from this region [PSD $\left.\left(\lambda_{\text {scat }}\right)\right]$ with respect to the total power [PSD $\left.\left(\lambda_{\text {tot }}\right)\right]$. This fraction is used as a weighting factor for the rms roughness, $\sigma_{\text {tot }}$, resulting in a value of the weighted rms roughness,

$\sigma_{\text {weight }}=\sigma_{\text {tot }} \times \operatorname{PSD}\left(\lambda_{\text {scat }}\right) / \operatorname{PSD}\left(\lambda_{\text {tot }}\right)$.

The current generated by longer (red) wavelengths shows a good correlation with the weighted rms values, as is shown in Fig. 1.

One of the limiting factors for further increasing the photogenerated current, therefore the cell efficiency, with

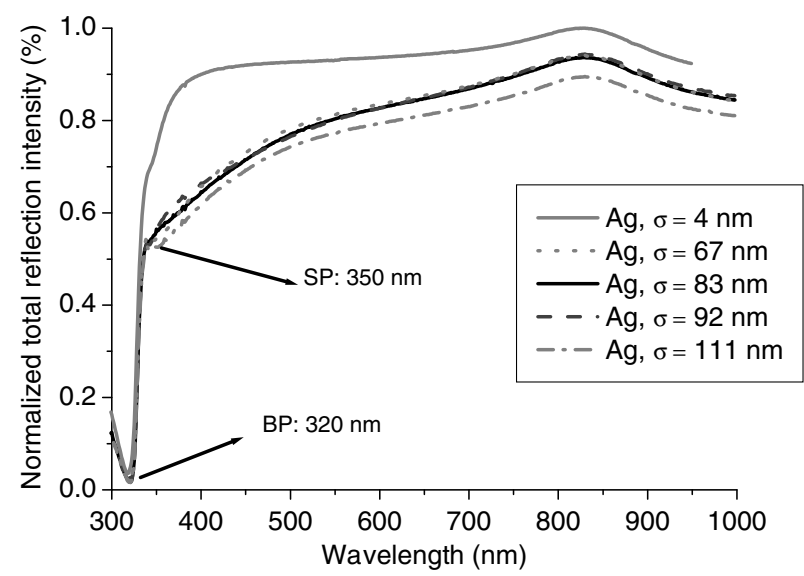

Fig. 2. Total reflection measurements of various types of back reflectors, showing indirectly the absorption peaks due to the surface plasmon (SP) and surface plasmon polaritons (SPP), as found by total reflection measurements with an integrating sphere. The intensity of the SPs is dependent on the dimensions of the morphology of the back contacts. increasing substrate roughness comes from free carrier absorption by the electrically conductive layers at the front and the back side of the cell, especially by the textured $\mathrm{Ag} / \mathrm{ZnO}$ surface [15]. We show in Fig. 2 the total reflection measurements of a number of back reflectors with different surface roughness. This figure shows indirectly the absorption peaks of the surface plasmons (SP) and surface plasmon polaritons (SPP) of the Ag layers. The SPP can have a broad resonance due to nanoprotrusions and be red shifted. The intensity of the SP absorption is dependent on the morphology of the back contacts. When the surface lateral feature size is in the range where maximum scattering happens, the surface plasmon absorption can be strongly enhanced, which compensates the increased scattering at $\mathrm{SS} / \mathrm{Ag} / \mathrm{ZnO}$ interfaces $[15,17]$.

The weighting of surface rms roughness only works, in principle, for the study of optical current enhancement. For the overall solar cell performance the material properties, especially those of the silicon layers, and the properties of interfaces play an important role. Fig. 3(a)-(d) shows the correlation between the surface rms (unweighted) roughness of a $\mathrm{Ag} / \mathrm{ZnO}$ coated Corning 1737 glass substrate and AM1.5 light $J-V$ characteristics (short circuit current density $J_{\mathrm{sc}}$, open circuit voltage $V_{\mathrm{oc}}$, fill factor $\mathrm{FF}$, and efficiency $\eta$ ) of a series of single junction nc-Si:H $\mathrm{n}-\mathrm{i}-\mathrm{p}$ cells. Except for the difference in substrate roughness, all deposition parameters were identical, with a constant $\mathrm{H}_{2}$ dilution ratio $R_{\mathrm{H}}$ of $0.953\left(R_{\mathrm{H}}\right.$ is defined as the gas flow ratio $\mathrm{H}_{2} /\left[\mathrm{SiH}_{4}+\mathrm{H}_{2}\right]$ ), and with an i-layer thickness of around $1.2 \mu \mathrm{m}$. From Fig. 3(d), it is clear that with the use of a rough substrate, the cell efficiency greatly a

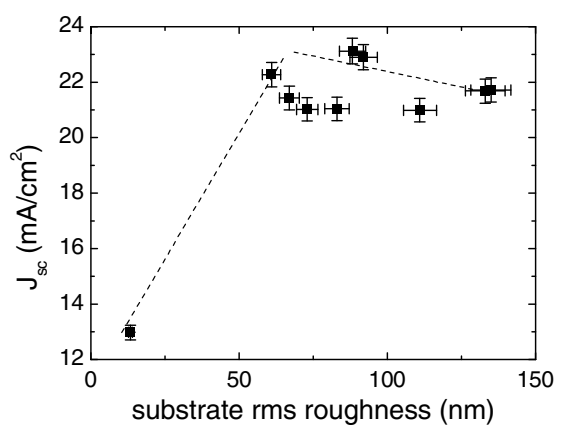

C

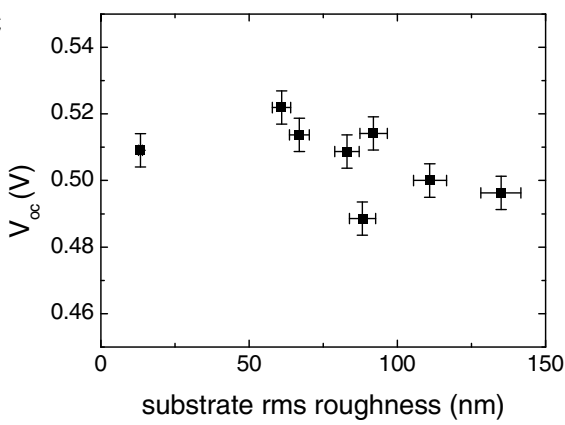

b

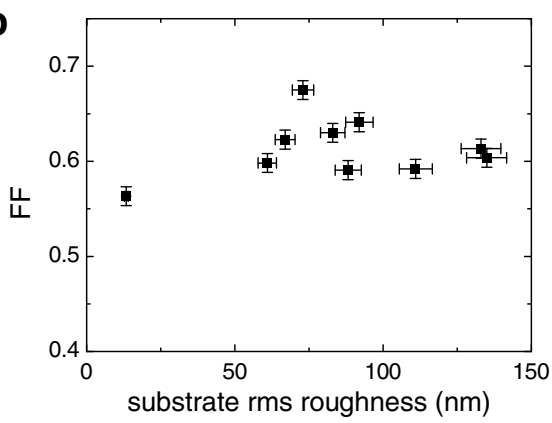

d

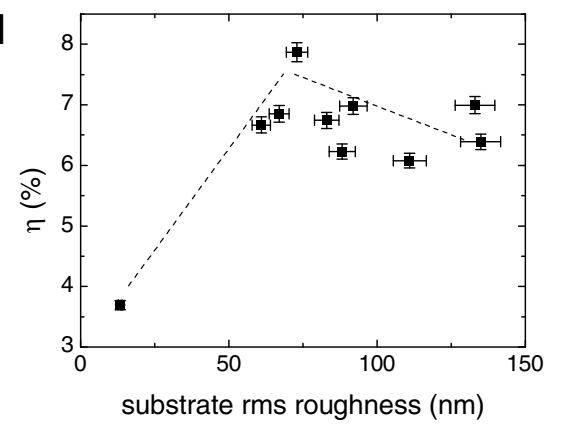

Fig. 3. AM1.5 J-V characteristics of nc-Si:H n-i-p solar cells with hot-wire i-layers and PECVD doped layers. The cells are made on Ag/ZnO coated Corning 1737 glass substrate. 
increases, from less than $4 \%$ on a nearly flat substrate to around $7 \%$ on a substrate with an rms roughness of $\sim 70 \mathrm{~nm}$. This is obviously due to the increase of $J_{\mathrm{sc}}$ (Fig. 3(a)), which in turn is due to the enhanced light scattering in the i-layer brought about by the rough substrate. The efficiency reaches its highest value at rms values between $60 \mathrm{~nm}$ and $90 \mathrm{~nm}$. With a further increase of the substrate roughness, the cell efficiency gradually goes down (Fig. 3(d)), similar to the trend observed for the $J_{\mathrm{sc}}$ (Fig. 3(a)). The FF for this set of samples shows a scattered distribution, but its maximum appears for cells made on a medium-rough substrate (Fig. 3(b) with rms between $60 \mathrm{~nm}$ and $90 \mathrm{~nm}$ ).

Another important reason for the limitation in cell efficiency with a further increase of the substrate roughness is that the silicon structure becomes more defective when deposited on a very rough substrate. This is particularly important for the nc-Si:H i-layer of the bottom cell, where substrate surface roughness has the strongest influence. Fig. 4 shows the typical structural defects observed from the cross-sectional TEM image of a nc-Si:H n-i-p solar cell deposited on a very rough $\mathrm{Ag} / \mathrm{ZnO}$ surface, from which one can clearly see the growth of defects in silicon layers

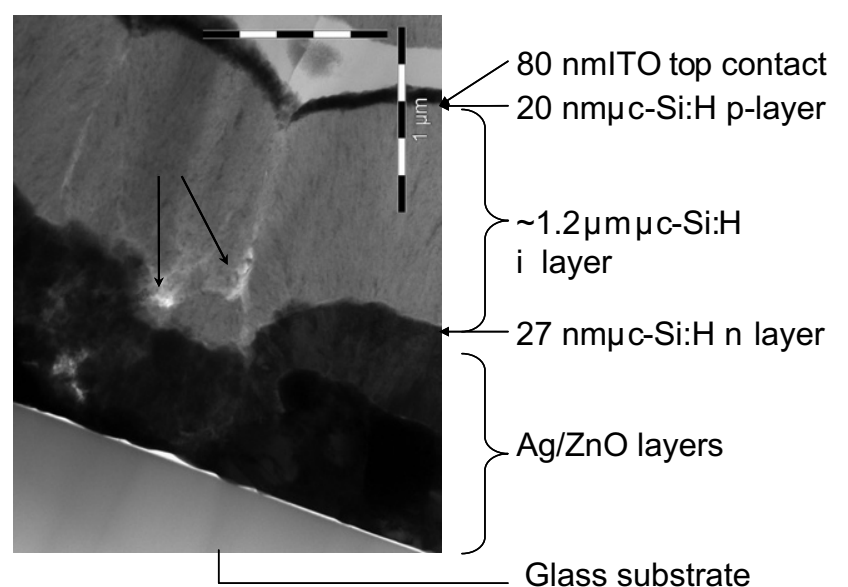

Fig. 4. Cross-sectional TEM image of a nc-Si:H n-i-p solar cell deposited on Corning glass coated $\mathrm{Ag} / \mathrm{ZnO}$ with a rough surface. The i-layer thickness is around $1.2 \mu \mathrm{m}$. The arrows point to the cavities that are not completely filled by silicon.
Table 1

The AM1.5 characteristics of the best single junction nc-Si:H n-i-p solar cells on flexible stainless-steel substrate (with $\mathrm{Ag} / \mathrm{ZnO}$ rough back reflector) with active layers made by HWCVD (this work) and PECVD (United Solar Ovonic LLC [19])

\begin{tabular}{lllll}
\hline Laboratory [Ref.] & $V_{\text {oc }}(\mathrm{V})$ & $J_{\text {sc }}\left(\mathrm{mA} / \mathrm{cm}^{2}\right)$ & $\mathrm{FF}$ & $\eta(\%)$ \\
\hline Utrecht [present work] & 0.545 & 23.6 & 0.669 & 8.6 \\
Unisolar [20] (VHF-PECVD) & 0.568 & 23.6 & 0.671 & 9.0 \\
\hline
\end{tabular}

near the edges of micro-valleys of the substrate surface. Structural defects of this kind may create shunting paths that largely deteriorate the cell performance [18]. In addition, electronic defects may be created in the bulk of the i-layers, reducing the solar cell fill factor and $V_{\mathrm{oc}}$. Evidence for such defect creation comes from the dark $J-V$ studies of this rms roughness series as is shown in Fig. 5, where the dark reverse saturation current density $J_{0}$ and diode quality $n$ of the cells shown in Fig. 3 are depicted. One can clearly see that with increasing substrate roughness, $J_{0}$ and $n$ values both increase, which is usually due to an increase of bulk recombination in the cell.

As an exception, the cell of which the XTEM image is shown in Fig. 4 contains a $\mathrm{ZnO}$ cover layer with a thickness of around $500 \mathrm{~nm}$, which modified the substrate surface morphology to a certain extent. The influence of the thin, $100-\mathrm{nm} \mathrm{ZnO}$ layers on the solar cell $J-V$ characteristics for the substrate rms roughness series discussed above can be considered negligible, since the sputtering conditions for these layers were kept constant within this series.

\subsection{Reverse $\mathrm{H}_{2}$ profiling in nc-Si:H bottom cells}

One of the key factors to obtain a high efficiency nc-Si:H cell is controlling the i-layer crystallinity. It has been shown that the maximum cell efficiency is normally achieved when the intrinsic nc-Si:H is made near the phase transition regime between amorphous and microcrystalline structure [19], possibly due to the better passivation of grain boundary defects in such materials. Unlike the cells with nc-Si:H absorber layers made with PECVD (RF or VHF), for $\mathrm{n}-\mathrm{i}-\mathrm{p}$ cells with a nc-Si:H i-layer made with hot-wire CVD we showed that the crystallinity can decrease with increasing the layer thickness, especially when the filament current is

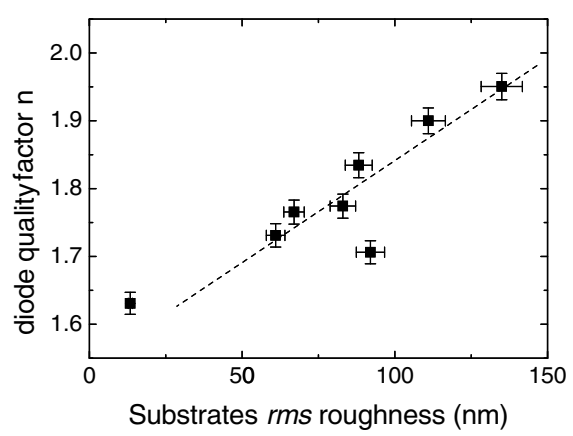

Fig. 5. Dependence of the dark saturation current density $J_{0}$ and the diode quality factor $n$ on the substrate rms roughness for the series shown in Fig. 3 . 

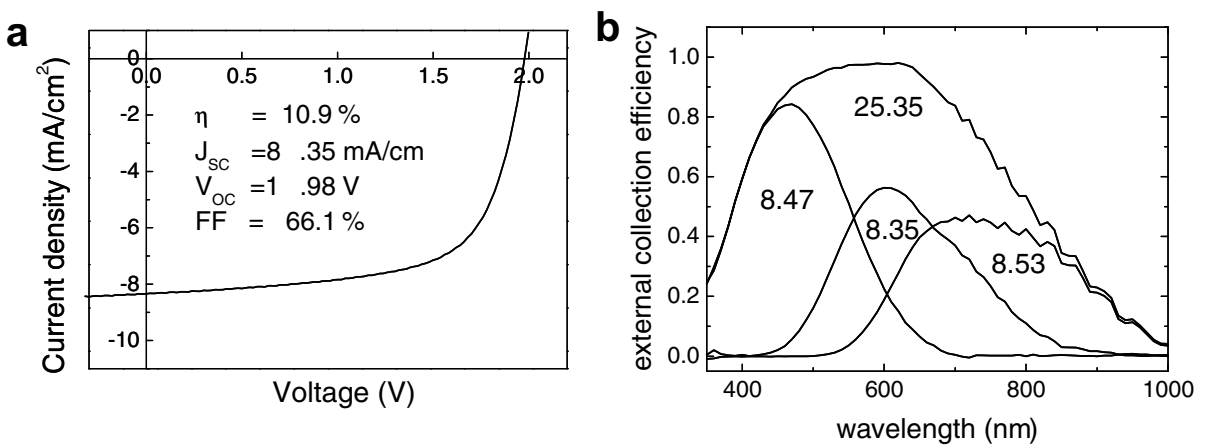

Fig. 6. $J-V$ (a) and external collection efficiency (b) of the best triple cell with hot-wire deposited silicon active layers. The values shown in the ECE graph (b) are in $\mathrm{mA} / \mathrm{cm}^{2}$.

held constant during i-layer deposition [9,14]. Although the dominating reason for this reverse development of nc-Si:H growth is not yet clear, we introduced a technique in which the hydrogen dilution ratio is increased instead of decreased. The preliminary results for cells made on stainless-steel foil have shown an AM1.5 efficiency of 8.6\%, which is close to the reported cell efficiency $(\sim 9.0 \%)$ with the same cell structure and on the same type of substrate ( $\mathrm{SS} / \mathrm{Ag} / \mathrm{ZnO}$ ) but with the absorber layer made with (VHF) PECVD [20] (Table 1). Since the cell structure and the substrate roughness for our samples are not optimal yet, we expect an increase of the efficiency after further optimization.

\subsection{Multijunction $n-i-p$ cells}

The knowledge acquired in developing high quality ncSi:H single junction cells has also been used to develop thin triple junction solar cells $(<2.5 \mu \mathrm{m})$ with a structure described in the previous section. The $J-V$ and spectral response of the best cell obtained within the project is shown in Fig. 6. The light soaking experiment for these samples has shown very stable behavior [21], with a relative efficiency degradation of only 3\%. The improved stability can be attributed to the triple junction structure, i.e. thinner i-layers in each subcell, and the use of high quality light absorbing materials, including that of hot-wire deposited proto-Si:H and nc-Si:H, and the PECVD deposited proto-SiGe:H. Compared to that published for cells with a similar structure but made with PECVD techniques [20], there is still room for improvement of the efficiency. One of the improvements is expected to come from optimization of the middle cell (which is still made with PECVD). At present the middle cell is a limiting factor for the triple cell performance [12].

\section{Conclusion}

We reviewed the main scientific challenges and achievements that we experienced while developing triple junction solar cells on flexible stainless-steel substrates with amorphous $\mathrm{Si}$ and nanocrystalline $\mathrm{Si}$ active layers made with hot-wire CVD. The result of our single junction nc-Si:H cells is very similar to the cells with the same structure on the same type of substrate but with the absorber layer made with (VHF) PECVD. We also developed very thin triple cells with $10.9 \%$ efficiency and stability within 3\% relative. Both results are at present the best reported for cells with similar structure but with hot-wire CVD deposited silicon active layers. We conclude that hot-wire deposited materials are very suitable for solar cells, and a significant step has been taken in developing this technique for utilization in industrial production.

\section{Acknowledgment}

The research described in this paper was financially supported by the Netherlands Agency for Energy and the Environment (SenterNovem).

\section{References}

[1] A.H. Mahan, J. Carapella, B.P. Nelson, R.S. Crandall, I. Balberg, J. Appl. Phys. 69 (1991) 6728.

[2] Q. Wang, E. Iwaniczko, Y. Xu, W. Gao, B.P. Nelson, A.H. Mahan, R.S. Crandall, H.M. Branz, Mater. Res. Soc. Symp. Proc. 609 (2000) A4.3.1.

[3] M.K. van Veen, R.E.I. Schropp, J. Appl. Phys. 93 (2003) 121.

[4] R.E.I. Schropp, M.K. van Veen, C.H.M. van der Werf, D.L. Williamson, A.H. Mahan, Mater. Res. Soc. Symp. Proc. 808 (2004) A8.4.

[5] R.L. Stolk, H. Li, R.H. Franken, J.J.H. Strengers, C.H.M. van der Werf, J.K. Rath, R.E.I. Schropp, J. Non-Cryst. Solids 352 (2006) 1933.

[6] S. Klein, F. Finger, R. Carius, M. Stutzmann, J. Appl. Phys. 98 (2005) 024905.

[7] J.K. Rath, F.D. Tichelaar, R.E.I. Schropp, Solid State Phenom. 67\&68 (1999) 465.

[8] S. Datta, Y. Xu, A.H. Mahan, H.M. Branz, J.D. Cohen, J. NonCryst. Solids 352 (2006) 1250.

[9] M.K. van Veen, C.H.M. van der Werf, R.E.I. Schropp, J. Non-Cryst. Solids 338-340 (2004) 655.

[10] R.L. Stolk, H. Li, R.H. Franken, C.H.M. van der Werf, J.K. Rath, R.E.I. Schropp, Mater. Res. Soc. Symp. Proc. 910 (2006) A.26.03.

[11] R.E.I. Schropp, K.F. Feenstra, E.C. Molenbroek, H. Meiling, J.K. Rath, Philos. Mag. B 76 (1997) 309.

[12] H. Li, R.L. Stolk, C.H.M. van der Werf, R.H. Franken, J.K. Rath, R.E.I. Schropp, J. Non-Cryst. Solids 352 (2006) 1941. 
[13] A. Gordijn, R. Jimenez Zambrano, J.K. Rath, R.E.I. Schropp, IEEE Trans. Elect. Dev. 49 (2002) 949.

[14] H. Li, R.H. Franken, R.L. Stolk, C.H.M. van der Werf, J.K. Rath, R.E.I. Schropp, Thin Solid Films (2007), doi:10.1016/ j.tsf.2007.06.195.

[15] R.H. Franken, R.L. Stolk, H. Li, C.H.M. van der Werf, J.K. Rath, R.E.I. Schropp, J. Appl. Phys. 102 (2007) 014503.

[16] R.H. Franken, Transparent conducting oxide contacts and textured metal back reflectors for thin film silicon solar cells, $\mathrm{PhD}$ thesis, Utrecht University, The Netherlands, 2006.

[17] G.R. Aizin, N.J.M. Horing, L.G. Mourokh, V.M. Kovalev, J. Appl. Phys. 96 (2004) 4225.
[18] H. Li, R.H. Franken, R. L Stolk, J.K. Rath, R.E.I. Schropp, Solid State Phenom. 131-133 (2008) 27.

[19] O. Vetterl, F. Finger, R. Carius, P. Hapke, L. Houben, O. Kluth, A. Lambertz, A. Mück, B. Rech, H. Wagner, Sol. Energy Mater. Sol. C 62 (2000) 97.

[20] Baojie Yan, Guozhen Yue, Subhendu Guha, Mater. Res. Soc. Symp. Proc. 989 (2007) A15.1.

[21] R.E.I. Schropp, H. Li, R.H.J. Franken, J.K. Rath, C.H.M. van der Werf, J.A. Schüttauf, R.L. Stolk, Mater. Res. Soc. Symp. Proc. 989 (2007) A15.3. 